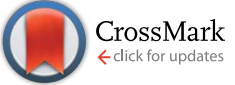

Cite this: RSC Adv., 2016, 6, 67662
Received 31st May 2016 Accepted 11th July 2016

DOI: 10.1039/c6ra14078e

www.rsc.org/advances

\title{
Highly efficient nitrogen-doped hierarchically porous carbon supported Ni nanoparticles for the selective hydrogenation of furfural to furfuryl alcohol $\uparrow$
}

\author{
Trupti V. Kotbagi, ${ }^{\text {*a }}$ Hanmant R. Gurav, ${ }^{\text {b }}$ Atul S. Nagpure, \\ Satyanarayana V. Chilukuri*b and Martin G. Bakker ${ }^{* a}$
}

\begin{abstract}
Nickel nanoparticles supported on nitrogen doped hierarchically porous carbon (Ni/CN) are found to be highly efficient and reusable catalysts for the selective hydrogenation of biomass-derived furfural to furfuryl alcohol (FA). Various characterization methods were used to study the structural and morphological features of the catalysts. Furfural conversion of $96 \%$ and $95 \%$ FA selectivity was obtained using a $5 \mathrm{wt} \% \mathrm{Ni} / \mathrm{CN}$ catalyst. This catalyst showed excellent recyclability without any loss in activity and FA selectivity when it was reused four times. The higher catalytic performance is attributed to the nitrogen incorporated hierarchical porous 3D carbon network.
\end{abstract}

\section{Introduction}

In view of decreasing fossil fuels and climate change, the use of efficient and environmentally benign technologies for the exploitation of renewable resources for the production of fuels and chemicals has become indispensable. ${ }^{1}$ Worldwide, significant research activity is focused on the development of strategies for transforming abundant lignocellulosic biomass into fuels and chemicals. ${ }^{1,2}$ Furfural is an important biomass-derived platform molecule, which can be synthesized by dehydration of xylose, a monosaccharide present in large amounts in the hemicellulose portion of lignocellulosic biomass. ${ }^{3}$ Furfural can be converted into a series of fuel additives and chemicals such as furfuryl alcohol (FA), tetrahydrofurfuryl alcohol (THFA), 2-methylfuran (MF), furan, 2-methyltetrahydrofuran (MTHF), tetrahydrofuran (THF), 1,5pentane diol, cyclopentanone, levulinic acid, etc. ${ }^{2,4} \mathrm{FA}$ is particularly attractive, due to a multitude of applications in the polymer and fine chemical industries. One route to synthesize FA is by selective hydrogenation of furfural (Scheme 1). The major applications of FA are in the synthesis of corrosion resistant fiberglass, acid proof bricks, thermostatic resins, liquid resins for galvanic bath tubs and corrosion resistant polymer concrete. ${ }^{5}$ It is also an essential intermediate in the manufacture of vitamin $\mathrm{C}$, dispersing agents, plasticizers, lysine and lubricants. ${ }^{5}$ Moreover, it can be employed as solvent for viscous pigments and as a component in rocket fuel. ${ }^{6}$

${ }^{a}$ Dept. of Chemistry, The University of Alabama, Tuscaloosa, Alabama, USA 35487-0336.E-mail: tkotbagi@crimson.ua.edu; bakker@as.ua.edu

${ }^{b}$ Inorganic Chemistry \& Catalysis Division, CSIR-National Chemical Laboratory, Dr Homi Bhabha Road, Pune - 411008, India.E-mail: sv.chilukuri@ncl.res.in

$\dagger$ Electronic supplementary information (ESI) available. See DOI: 10.1039/c6ra14078e
Commercially, copper chromite $(\mathrm{Cu}-\mathrm{Cr})$ catalysts have been used for selective hydrogenation of furfural to FA in industry for more than five decades. ${ }^{7}$ The main disadvantage of $\mathrm{Cu}-\mathrm{Cr}$ catalysts is their high toxicity, which can cause problems with both handling and disposal of spent catalyst. As a result, there is increased scientific interest in the design of Cr-free, environmentally friendly, active and selective catalysts for furfural hydrogenation to FA. Several research groups have studied the hydrogenation of furfural to FA using various supported metal and amorphous alloys as catalysts, mostly copper chromite, $\mathrm{Cu}, \mathrm{Ni}, \mathrm{Co}, \mathrm{Mo}, \mathrm{Pd}, \mathrm{Rh}, \mathrm{Ir}, \mathrm{Re}, \mathrm{Ru}$ and $\mathrm{Pt}_{\text {catalysts }}{ }^{7-20}$ and $\mathrm{Ni}-\mathrm{P}-\mathrm{B}, \mathrm{Ni}-\mathrm{B}$ and $\mathrm{Ni}-\mathrm{P}$ ultrafine materials. $^{21}$ Often a promoter or a second metal is added to increase the catalytic activity and/or the product selectivity. Among them, systems based on Co-modified with Mo, ${ }^{15}$ $\mathrm{Cu}-\mathrm{Fe},{ }^{22} \mathrm{Cu}-\mathrm{Ca},{ }^{23} \mathrm{Ni}-\mathrm{Fe}$ bimetallic catalysts, ${ }^{24}$ promoters like $\mathrm{Zn}, \mathrm{Cr}, \mathrm{Co}, \mathrm{Ni}, \mathrm{Pd}$ and $\mathrm{Fe}$ in $\mathrm{Cu}-\mathrm{MgO},{ }^{25} \mathrm{Fe}$ or $\mathrm{Ce}$ in $\mathrm{Ni}-\mathrm{B}^{26,27}$

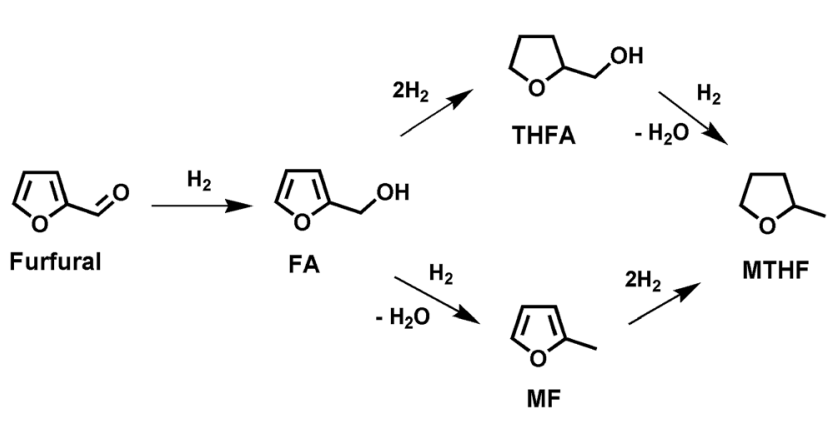

Scheme 1 Reaction pathways for furfural hydrogenation. Compounds: furfuryl alcohol (FA); tetrahydrofurfuryl alcohol (THFA); 2-methylfuran (MF); 2-methyltetrahydrofuran (MTHF). 
have shown high furfural conversion (close to 100\%) and good FA selectivity. However, the main drawbacks are that most of the reported catalysts require higher $\mathrm{H}_{2}$ pressures and are not recyclable. Hence, there is a need to develop an environmentally friendly and economically feasible process for the selective hydrogenation of furfural to FA.

The large majority of the studies reported above used metal oxide supported or bimetallic catalysts with only a single study using carbon as a support. ${ }^{16}$ For many organic molecules the less hydrophilic nature of many carbon supports would be expected to be advantageous. Carbon supports have been successfully used for selective hydrogenation of other unsaturated aldehydes including cinnamaldehyde, where the $\mathrm{C}=\mathrm{C}$ bond, the carbonyl group and the aromatic ring can potentially all be reduced. ${ }^{28-33}$ The majority of the studies used platinum or palladium, although one study that used nickel supported on carbon nanofibers ${ }^{32}$ reported predominantly reduction of the $\mathrm{C}=\mathrm{C}$ bond. Selective reduction of the carbonyl group to give cinnamyl alcohol was reported for platinum supported on mesoporous carbon promoted by iron or zinc. ${ }^{31}$

The nature of the carbon support can also impact the activity and selectivity of a catalyst, beyond mass transport and surface area effects that depend upon the structure and morphology. For the reaction of cinnamaldehyde using platinum supported on carbon nanofibers Toebes et al. found that decreasing concentrations of surface oxygen gave increases in selectivity for $\mathrm{C}=\mathrm{C}$ bond reduction..$^{28,30}$ They were able to largely rule out any electronic impact of the oxygen based on XPS and hydrogen chemisorption experiments. The carbon support can also impact the activity of supported metal nanoparticles by affecting the nanoparticle dispersion and stability ${ }^{34}$ particularly when doping atoms such as nitrogen are incorporated into the carbon. ${ }^{35}$ Moreover, the advantages of using hierarchically porous catalysts is the presence of networks of micrometer scale pores that provide efficient transport of reactants and products into and out of the catalyst, coupled to nanometer scale pores that provide large surface area. The micrometer scale pores are expected to make the catalyst more tolerant to deactivation by clogging.

Recently, we successfully designed nitrogen doped hierarchically porous carbon (CN) supported Ni materials using a facile one-pot co-gelation sol-gel technique. ${ }^{36}$ The present study, reports the effectiveness of $\mathrm{Ni} / \mathrm{CN}$ for the liquid-phase hydrogenation of furfural to FA (Scheme 2). Herein, 5 wt $\%$ $\mathrm{Ni} / \mathrm{CN}$ catalyst gave $96 \%$ furfural conversion and $95 \%$ FA selectivity along with good recyclability in the conversion of furfural to FA. The influence of various reaction parameters on the catalyst performance was also investigated by varying the reaction temperature, solvent, $\mathrm{Ni}$ content of the catalyst, $\mathrm{H}_{2}$ pressure, etc.

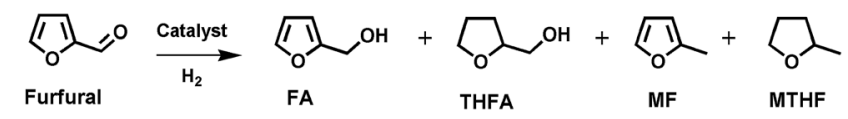

Scheme 2 Hydrogenation of furfural using $\mathrm{Ni} / \mathrm{CN}$ catalysts.

\section{Experimental section}

\section{Chemicals}

Ethanol (99\%) and tri-block co-polymer Pluronic F127 (99.9\%) were procured from Sigma Aldrich, St Louis, MO, USA. Formalin (>99\%) was obtained from Macron Chemicals, Philipsburg, NJ, USA. Resorcinol (99.9\%) was procured from Riëdel-De Haën Ag Seelze, Hannover, Germany. 1,6-Diamino hexane (99.5\%) and nickel(II) acetate tetrahydrate (99\%) were obtained from Acros Organics, New Jersey, USA. Methanol, 2-propanol, THF and 1,2-dimethoxyethane were procured from Loba Chemie, India. Furfural, FA, THFA, MF, and MTHF were obtained from Alfa Aesar, India.

\section{Preparation of $\mathrm{CN}$ and $\mathrm{Ni} / \mathrm{CN}$ catalysts}

$\mathrm{CN}$ and $\mathrm{Ni} / \mathrm{CN}$ monolithic catalysts with different $\mathrm{Ni}$ content were prepared by using a one-pot co-gelation sol-gel technique according to the reported literature (see ESI $\dagger$ ). ${ }^{36}$

\section{Characterization techniques}

The characterization of the catalysts was carried out by the following techniques.

The X-ray diffraction (XRD) patterns of materials were collected using a PANalytical X'pert Pro dual goniometer. The data were recorded in the $2 \theta$ range of $5-90^{\circ}$ with $0.02^{\circ}$ step size. Nickel filtered $\mathrm{CuK} \alpha(\lambda=1.5406 \AA, 40 \mathrm{kV}, 30 \mathrm{~mA})$ radiation was used and the data collection was carried out using a flat holder in Bragg-Brentano geometry.

The nitrogen $\left(\mathrm{N}_{2}\right)$ physisorption analysis were carried out using a Quantachrome Nova 2200e pore size analyzer (Boynton Beach, FL) at $-196{ }^{\circ} \mathrm{C}$ with He mode to determine BET surface area and void volume of the samples, respectively. Interpretation of the isotherms was done with Quantachrome NovaWin software version 11.1 (NL-DFT). ${ }^{36}$ The BJH method was used to determine the average pore diameter of the samples.

The Raman spectra of the samples were collected using LabRAM HR800 (Jobin Yvon Horiba, France) with the laser wavelength of $632.84 \mathrm{~nm}$ (He-Ne Laser, $20 \mathrm{~mW}$ of power).

Transmission electron microscope (TEM) images were collected using an FEI Technai TF-30 instrument operating at $300 \mathrm{kV}$. For TEM analysis, the sample was prepared by placing a droplet of the sample suspension prepared in 2-propanol using ultrasonication on a carbon coated copper grid and by leaving them for drying at room temperature.

The amount of Ni present in the samples was estimated by Inductively Coupled Plasma-Optical Emission Spectrometry (ICP-OES) (Spectro Arcos, FHS-12).

Fourier-transform infrared (FT-IR) spectra of the samples were recorded on a Bruker Vertex 70FT-IR instrument.

\section{Catalytic tests}

The monoliths were ground well before using for the catalytic reactions. All the reactions were carried out in a $100 \mathrm{~mL}$ Parr autoclave (SS316). In a typical experiment, furfural (5 mmol), solvent $(25 \mathrm{~mL})$ and the required amount of freshly reduced 
catalyst powder (reduction at $350{ }^{\circ} \mathrm{C}$ for $4 \mathrm{~h}$ in $\mathrm{H}_{2}$ atmosphere) were introduced into the reactor vessel. The reactor contents were mixed thoroughly and the reactor was sealed, purged two times with $\mathrm{H}_{2}$ and pressurized with the required $\mathrm{H}_{2}$ pressure and the reaction was conducted at the desired temperature under continuous stirring (800 rpm). Liquid samples were collected periodically and analyzed by a GC (Agilent 7890A) equipped with a FID detector having CP Sil 8 CB capillary column (30 m length, $0.25 \mathrm{~mm}$ diameter). Products identification was done using authentic standards and by using GC-MS (Shimadzu, GCMS-QP2010 Ultra; HP-5 column; $30 \mathrm{~m}$ length, $0.25 \mathrm{~mm}$ diameter).

\section{Results and discussion}

\section{Structural characteristics of the catalysts}

The XRD patterns of the $\mathrm{CN}$ and as-reduced $\mathrm{Ni} / \mathrm{CN}$ catalysts with different $\mathrm{Ni}$ content are shown in Fig. 1a. A broad diffraction peak at around $2 \theta=25^{\circ}$ and a weak reflection around $2 \theta=44^{\circ}$ were observed for $\mathrm{CN}$, corresponding to the (002) and (100) planes of the graphite lattice, respectively. ${ }^{37}$ The XRD pattern of $1 \mathrm{wt} \% \mathrm{Ni} / \mathrm{CN}$ catalyst was similar to that of $\mathrm{CN}$ and did not contain any diffraction peaks related to the metallic Ni. The diffraction peaks of $\mathrm{Ni}$ in $2.5 \mathrm{wt} \% \mathrm{Ni} / \mathrm{CN}$ were weak. However, significant sharp diffraction peaks of $\mathrm{Ni}$ at $2 \theta=44.5$ and $51.8^{\circ}$
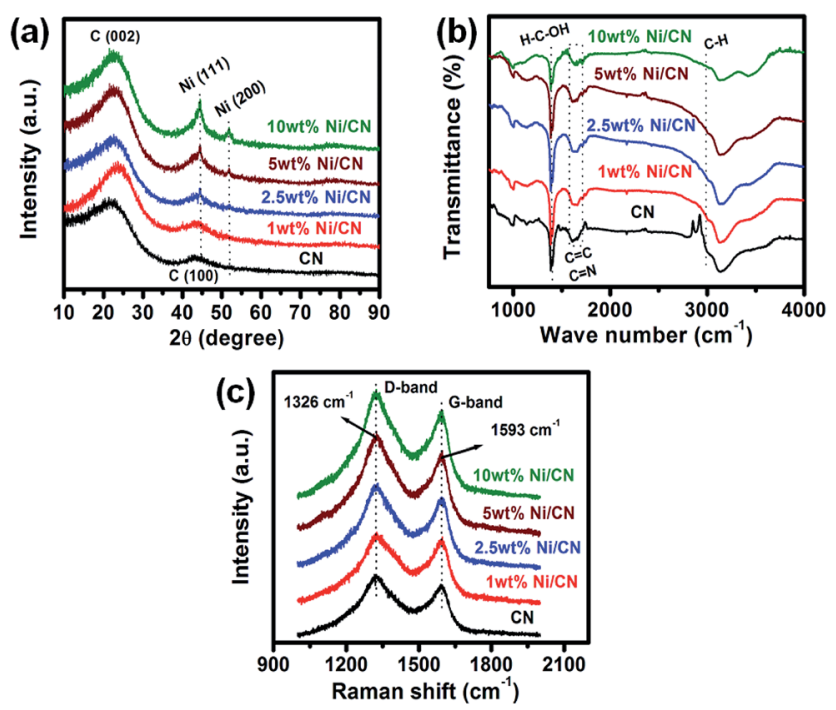

Fig. 1 (a) XRD patterns, (b) FT-IR and (c) Raman spectra of the CN and freshly reduced Ni catalysts. were detected in $5 \mathrm{wt} \% \mathrm{Ni} / \mathrm{CN}$ and $10 \mathrm{wt} \% \mathrm{Ni} / \mathrm{CN}$ catalysts, which were assigned to (111) and (200) crystalline planes of metallic Ni, respectively. This clearly suggested an increase in the crystallite size of $\mathrm{Ni}$ with increased in Ni loading. The peaks associated with nickel oxides were not observed in any of the $\mathrm{Ni}$ catalysts. Additionally, slight shift was observed in the peak corresponding to the (002) planes of graphitic carbon on the incorporation of $\mathrm{Ni}$ metal to the hierarchically porous carbon support $(\mathrm{Ni} / \mathrm{CN})$. Metal-induced catalysed graphitization of carbon has been reported earlier by Hoekstra et al. ${ }^{38}$ The report suggests the presence of $\mathrm{Ni}$ metal enhances the extent of catalytic graphitization of carbon thereby introducing some microcrystallinity to the amorphous carbon support. In the present case the addition of $\mathrm{Ni}$ metal on to the carbon support might have enhanced the graphitic nature of the support along with the crystallinity thereby resulting in a slight shift in the peak position with relatively sharper peak centred at $\sim 25.2^{\circ}$ compared to the XRD pattern of $\mathrm{CN}$. As reported earlier, $\mathrm{CN}$ and $1 \mathrm{wt} \% \mathrm{Ni} / \mathrm{CN}$ both showed type IV adsorption-desorption isotherms, showing the presence of mesopores. ${ }^{36}$ The other textural parameters and physico-chemical features of the samples are summarized in Table 1. The SEM images of CN and $\mathrm{Ni}$ /CN samples also showed the presence of macropores as reported earlier. ${ }^{36}$

The FT-IR spectroscopic studies were carried out to identify the functional groups present in $\mathrm{CN}$ and Ni catalysts (Fig. 1b). The peaks at 1384 and $2990 \mathrm{~cm}^{-1}$ are related to the deformation vibration of $\mathrm{H}-\mathrm{C}-\mathrm{OH}$ and the asymmetrical stretching vibration of $\mathrm{C}-\mathrm{H}\left(-\mathrm{CH}_{2}\right)$, respectively. ${ }^{36}$ The bands falling in the range of $1600-1700 \mathrm{~cm}^{-1}$ are assigned to the $\mathrm{C}=\mathrm{C}$ and $\mathrm{C}=\mathrm{N}$ vibrations. ${ }^{36}$ The peak at $3150 \mathrm{~cm}^{-1}$ shows the presence of hydroxyl groups. The band at $3500 \mathrm{~cm}^{-1}$ in the FT-IR spectra could be due to the stretching vibration of hydroxyl group, which is in association with water molecules. And the variation of the magnitude of this band could be because of different water content in the sample. Raman spectroscopy was employed to study the graphitic nature of the carbon materials and the results are given in the Fig. 1c. It consists of characteristic Dand G-bands of disordered graphitic carbon samples, situated at 1326 and $1593 \mathrm{~cm}^{-1}$, respectively. ${ }^{37}$ The G-band indicates the graphitic structure of carbons whereas the D-band reflects defects in carbon. ${ }^{37}$ The TEM images and Ni particle size distribution of the as-reduced Ni catalysts are depicted in Fig. 2. The average particle size of Ni nanoparticles in $1 \mathrm{wt} \%, 2.5 \mathrm{wt} \%$, $5 \mathrm{wt} \%$ and $10 \mathrm{wt} \% \mathrm{Ni} / \mathrm{CN}$ was found to be $2.8,4.6,6.9$ and $10.1 \mathrm{~nm}$, respectively.

Table 1 Textural properties and Ni metal characteristics of the catalysts

\begin{tabular}{llllll}
\hline Catalyst & Ni content $^{a}(\mathrm{wt} \%)$ & BET surface area $\left(\mathrm{m}^{2} \mathrm{~g}^{-1}\right)$ & Ave. pore diam. (nm) & 'N' content ${ }^{b}\left(\mathrm{wt}^{2}\right)$ & Ave. Ni particle size $^{c}(\mathrm{~nm})$ \\
\hline $\mathrm{CN}$ & - & 560 (ref. 36) & 5.5 (ref. 36) & 2.8 & - \\
$1 \mathrm{wt} \% \mathrm{Ni} / \mathrm{CN}$ & 0.82 & 458 (ref. 36) & 3.3 (ref. 36) & 2.7 & 2.8 \\
$2.5 \mathrm{wt} \% \mathrm{Ni} / \mathrm{CN}$ & 2.21 & 429 (ref. 36) & 3.2 (ref. 36) & 2.7 & 4.6 \\
$5 \mathrm{wt} \% \mathrm{Ni} / \mathrm{CN}$ & 4.32 & 374 (ref. 36) & 3.1 (ref. 36) & 2.5 & 6.9 \\
$10 \mathrm{wt} \% \mathrm{Ni} / \mathrm{CN}$ & 8.16 & 341 & 3.1 & 2.4 & 10.1
\end{tabular}

${ }^{a}$ Determined by ICP-OES. ${ }^{b}$ Calculated by elemental analysis. ${ }^{c}$ Calculated based on TEM. 

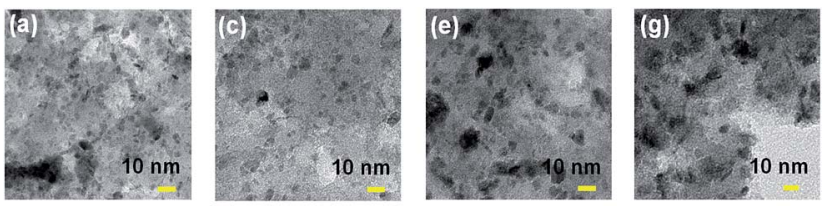

(b)

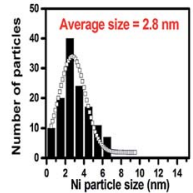

(d)

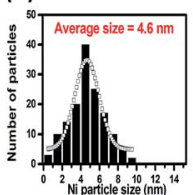

(f)

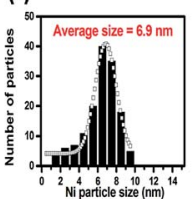

(h)

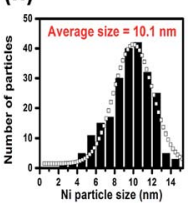

Fig. 2 TEM image and the Ni nanoparticles size distribution for $1 \mathrm{wt} \%$ $\mathrm{Ni} / \mathrm{CN}$ ( $a$ and b), $2.5 \mathrm{wt} \% \mathrm{Ni} / \mathrm{CN}$ (c and d), $5 \mathrm{wt} \% \mathrm{Ni} / \mathrm{CN}$ (e and f) and 10 $w t \% \mathrm{Ni} / \mathrm{CN}$ (g and $\mathrm{h}$ ), respectively.

\section{Catalytic hydrogenation of furfural to FA using Ni/CN catalysts}

Effect of reaction temperature. The effect of reaction temperature on furfural conversion and FA selectivity was investigated by varying the temperature in the $160-220^{\circ} \mathrm{C}$ range over $5 \mathrm{wt} \% \mathrm{Ni} / \mathrm{CN}$ catalyst (Fig. 3). The furfural conversion was enhanced with increasing the temperature and with increasing reaction time (Fig. 3a). After $4 \mathrm{~h}$ of reaction, the furfural conversion was improved from 46 to $100 \%$, as the reaction temperature elevated from 160 to $220{ }^{\circ} \mathrm{C}$. The reaction temperature has considerable influence on FA selectivity (Fig. 3b). When the reaction was performed at 160 and $180{ }^{\circ} \mathrm{C}$, an excellent FA selectivity (95-98\%) was observed. At $200{ }^{\circ} \mathrm{C}$, the FA selectivity was nearly $95 \%$ up to $4 \mathrm{~h}$, and then decreased to $87 \%$ after 6 h. However, FA selectivity dropped from 89 to $70 \%$ as a function of reaction time, when the reaction was carried out at a higher temperature $\left(220^{\circ} \mathrm{C}\right)$. This decrease in FA selectivity was due to the formation of THFA and MF at higher temperature as well as at longer reaction time. Therefore, $200{ }^{\circ} \mathrm{C}$ was found to be the optimum temperature to achieve high furfural conversion (96\%) and good FA selectivity (95\%) after $4 \mathrm{~h}$ of reaction time.

Effect of $\mathrm{H}_{2}$ pressure. The effect of $\mathrm{H}_{2}$ pressure on furfural hydrogenation was studied over 5 wt $\%$ Ni/CN catalyst by changing the pressure in the range of $2-13$ bar at $200{ }^{\circ} \mathrm{C}$ (Fig. 4). When the reaction was carried out at lower $\mathrm{H}_{2}$ pressure $(2,5$ and 7 bar), furfural conversion was low, which was enhanced at higher $\mathrm{H}_{2}$ pressure reaching a maximum of $100 \%$ at 10 bar
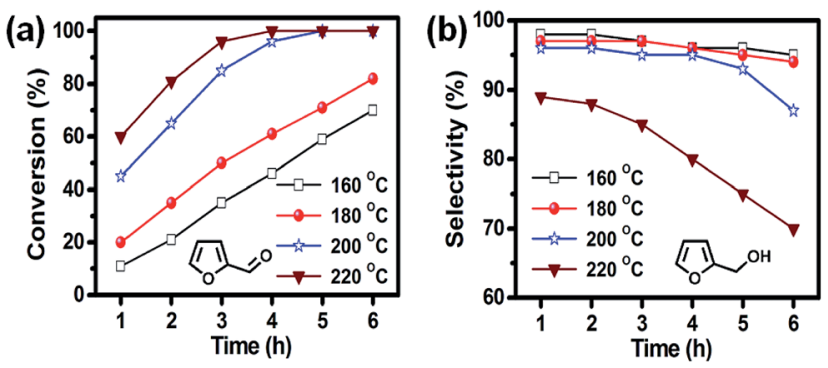

Fig. 3 Effect of reaction temperature on (a) furfural conversion and (b) FA selectivity. Reaction conditions: furfural $(5 \mathrm{mmol})$; catalyst ( $5 \mathrm{wt} \%$ $\mathrm{Ni} / \mathrm{CN}, 80 \mathrm{mg}$ ); solvent (2-propanol, $25 \mathrm{~mL}$ ); $\mathrm{H}_{2}$ pressure (10 bar).
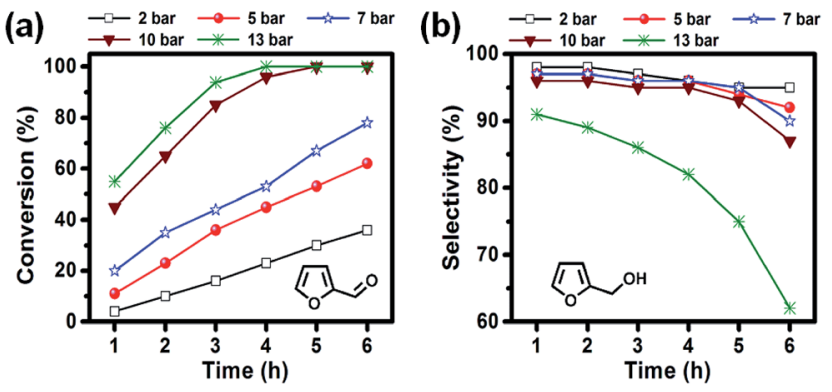

Fig. 4 Effect of $\mathrm{H}_{2}$ pressure on (a) furfural conversion and (b) FA selectivity. Reaction conditions: furfural $(5 \mathrm{mmol})$; catalyst ( $5 \mathrm{wt} \% \mathrm{Ni} /$ $\mathrm{CN}, 80 \mathrm{mg}$ ); solvent (2-propanol, $25 \mathrm{~mL}$ ); temperature $\left(200^{\circ} \mathrm{C}\right)$.

pressure after $5 \mathrm{~h}$ (Fig. 4a). On increasing the $\mathrm{H}_{2}$ pressure to 13 bar, $100 \%$ furfural conversion was achieved over a shorter reaction time ( $4 \mathrm{~h})$. The $\mathrm{H}_{2}$ pressure has a significant impact on FA selectivity, as shown in Fig. $4 \mathrm{~b}$. At lower $\mathrm{H}_{2}$ pressure (2 to 10 bar), the FA selectivity was found to vary from 87 to $98 \%$. Increasing the $\mathrm{H}_{2}$ pressure further to 13 bar, the FA selectivity was adversely affected, mostly due to the enhanced rate of consecutive ring hydrogenation of FA, leading to the formation of THFA in substantial amounts. Hence, an optimum $\mathrm{H}_{2}$ pressure of 10 bar was chosen to obtain high furfural conversion and good FA selectivity.

Effect of solvent. The effect of solvent on the liquid-phase hydrogenation of furfural to FA was investigated over $5 \mathrm{wt} \%$ $\mathrm{Ni} / \mathrm{CN}$ catalyst at $200{ }^{\circ} \mathrm{C}$ and at 10 bar $\mathrm{H}_{2}$ pressure (Table 2). Solvents with a different chemical nature; protic (methanol and 2-propanol) and aprotic polar (THF and 1,2-dimethoxyethane (1,2-DME)) solvents, were used to study the effect of solvent on furfural hydrogenation activity. The results given in Table 2 clearly show that the catalyst activity is strongly solvent dependent. The following catalytic activity order was noticed: 2-propanol $>$ methanol $>$ THF $>$ 1,2-DME. Thus, it can be seen that the furfural conversion was relatively higher in protic solvents than in aprotic solvents. The higher observed rate of furfural hydrogenation could be attributed to the activation of the furfural molecule via hydrogen bonding between the carbonyl oxygen of furfural and the hydroxyl group of the alcohol. ${ }^{39}$ When methanol was used as a solvent, considerable amounts $(20 \%)$ of ethers and acetals were detected in the reaction mixture, whereas these products were not observed with 2-propanol solvent. When 2-propanol was employed as a solvent higher catalytic activity was found, giving $96 \%$ furfural conversion and 95\% FA selectivity (entry 4, Table 2). Although 2-propanol is itself a well-known hydrogen transfer reagent, the result suggested that the effect of transfer hydrogenation was not significant under the studied reaction conditions (entry 5 , Table 2).

Effect of catalyst amount. Experiments were conducted by varying the amount of the $5 \mathrm{wt} \% \mathrm{Ni} / \mathrm{CN}$ catalyst between 40 and $120 \mathrm{mg}$ at $200{ }^{\circ} \mathrm{C}$ while keeping the same furfural amount (Fig. 5). The results showed that furfural conversion increased with increasing amount of catalyst. When $80 \mathrm{mg}$ catalyst was used, 96\% furfural conversion and 95\% FA selectivity was 
Table 2 Hydrogenation of furfural in different solvents over 5 wt $\% \mathrm{Ni} / \mathrm{CN}$ catalyst $^{a}$

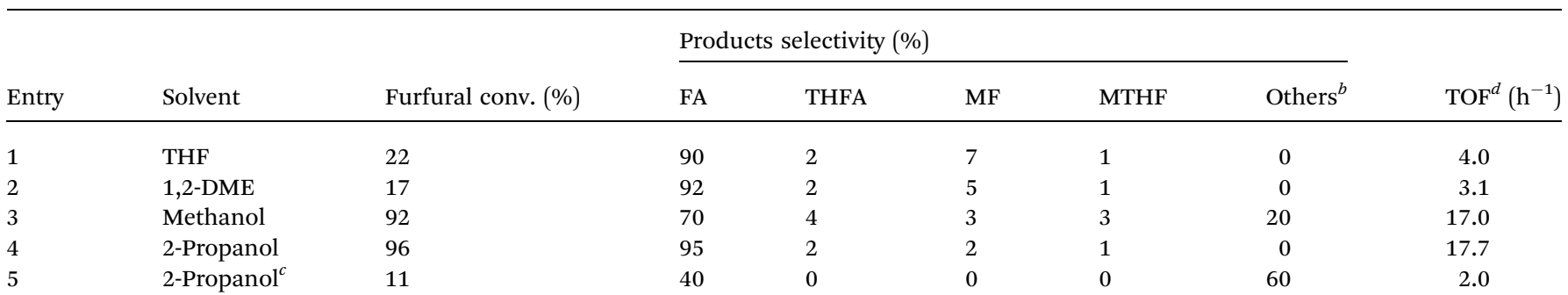

${ }^{a}$ Reaction conditions: molar ratio of furfural to Ni (74); solvent $(25 \mathrm{~mL})$; time $(4 \mathrm{~h}) ; \mathrm{H}_{2}$ pressure $(10 \mathrm{bar})$; temperature $\left(200{ }^{\circ} \mathrm{C}\right) .{ }^{b}$ Includes ethers and acetals. ${ }^{c}$ In the absence of $\mathrm{H}_{2}$ (10 bar $\mathrm{N}_{2}$ pressure was used). ${ }^{d}$ TOF $=$ turnover frequency (moles of furfural converted per mole of Ni metal per unit hour).
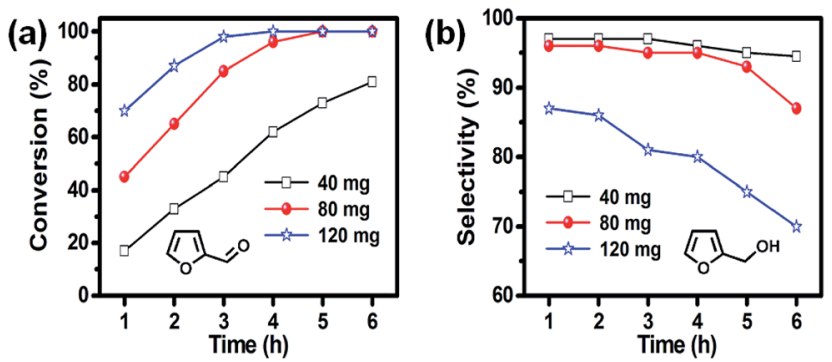

Fig. 5 Effect of catalyst content on (a) furfural conversion and (b) FA selectivity. Reaction conditions: furfural $(5 \mathrm{mmol})$; catalyst ( $5 \mathrm{wt} \% \mathrm{Ni} /$ $\mathrm{CN}$ ); solvent (2-propanol, $25 \mathrm{~mL}$ ); $\mathrm{H}_{2}$ pressure (10 bar); temperature $\left(200{ }^{\circ} \mathrm{C}\right)$.

obtained after $4 \mathrm{~h}$ of reaction. However, when the catalyst amount was further increased to $120 \mathrm{mg}$, lower FA selectivity was observed. These results clearly showed that higher catalyst loading accelerates the rate of side reactions, leading to the formation of unwanted by-products such as MF, THFA and MTHF, which in turn affects the FA selectivity.

Effect of Ni loading. To optimize the Ni content of the catalyst, catalysts with different $\mathrm{Ni}$ loadings $(1,2.5,5$ and $10 \mathrm{wt} \%)$ supported on $\mathrm{CN}$ were prepared and evaluated for furfural hydrogenation (Table 3). $5 \mathrm{wt} \% \mathrm{Ni} / \mathrm{CN}$ catalyst displayed relatively better activity, yielding $96 \%$ furfural conversion with $95 \%$ FA selectivity (entry 3, Table 3). However, under similar operating

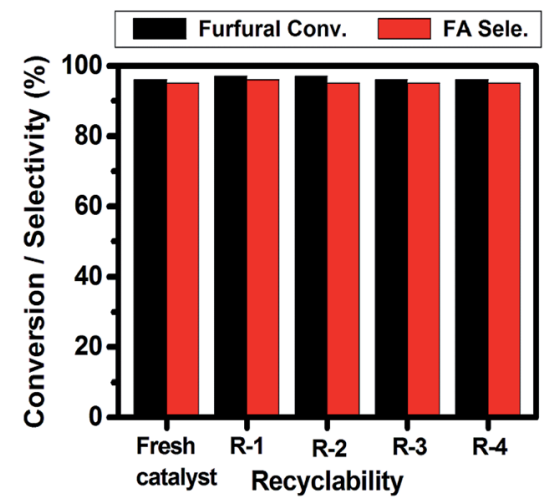

Fig. 6 Recyclability experiments with $5 \mathrm{wt} \% \mathrm{Ni} / \mathrm{CN}$ catalyst in the hydrogenation of furfural to FA. Reaction conditions: molar ratio of furfural to $\mathrm{Ni}$ (74); solvent (2-propanol, $25 \mathrm{~mL}$ ); time (4 h); $\mathrm{H}_{2}$ pressure (10 bar); temperature $\left(200^{\circ} \mathrm{C}\right)$.

conditions, FA selectivities observed were 70,83 and $75 \%$ at 45 , 68 and $100 \%$ furfural conversion over $1 \mathrm{wt} \%, 2.5 \mathrm{wt} \%$ and $10 \mathrm{wt} \%$ $\mathrm{Ni} / \mathrm{CN}$ catalyst, respectively (entry 1,2 and 4 , Table 3 ). Interestingly, higher selectivity for MF was observed over $1 \mathrm{wt} \%$ and $2.5 \mathrm{wt} \% \mathrm{Ni}$ catalysts (entries 1 and 2, Table 3). A possible reason for this could be that the smaller Ni particles $(2.8$ and $4.6 \mathrm{~nm})$ have some deoxygenation ability in the conversion of hydroxymethyl group $\left(-\mathrm{CH}_{2} \mathrm{OH}\right)$ of $\mathrm{FA}$, which leads to the formation of MF. On the other hand, considerable selectivity for THFA

Table 3 Hydrogenation of furfural over Ni/CN catalysts with varying Ni loadings ${ }^{a}$

\begin{tabular}{|c|c|c|c|c|c|c|c|c|}
\hline \multirow[b]{2}{*}{ Entry } & \multirow[b]{2}{*}{ Catalyst } & \multirow[b]{2}{*}{ Furfural conv. (\%) } & \multicolumn{5}{|c|}{ Products selectivity (\%) } & \multirow[b]{2}{*}{$\operatorname{TOF}^{d}\left(\mathrm{~h}^{-1}\right.$} \\
\hline & & & FA & THFA & MF & MTHF & Others $^{b}$ & \\
\hline 1 & $1 \mathrm{wt} \% \mathrm{Ni} / \mathrm{CN}$ & 45 & 70 & 1 & 23 & 4 & 2 & 8.3 \\
\hline 2 & $2.5 \mathrm{wt} \% \mathrm{Ni} / \mathrm{CN}$ & 68 & 83 & 1 & 12 & 3 & 1 & 12.6 \\
\hline 3 & 5 wt $\% \mathrm{Ni} / \mathrm{CN}$ & 96 & 95 & 2 & 2 & 1 & 0 & 17.7 \\
\hline 4 & $10 \mathrm{wt} \% \mathrm{Ni} / \mathrm{CN}$ & 100 & 75 & 22 & 0 & 3 & 0 & 18.5 \\
\hline 5 & $\mathrm{CN}^{c}$ & 15 & 20 & 0 & 0 & 0 & 80 & - \\
\hline 6 & No catalyst & 9 & 0 & 0 & 0 & 0 & 100 & - \\
\hline
\end{tabular}

${ }^{a}$ Reaction conditions: molar ratio of furfural to Ni (74); solvent (2-propanol, $\left.25 \mathrm{~mL}\right)$; time $(4 \mathrm{~h}) ; \mathrm{H}_{2}$ pressure $(10 \mathrm{bar})$; temperature $\left(200{ }^{\circ} \mathrm{C}\right) .{ }^{b} \mathrm{It}$ includes ethers, acetals and some condensation compounds. ${ }^{c} 80 \mathrm{mg} .{ }^{d}$ Turnover frequency (moles of furfural converted per mole of Ni metal per unit hour). 
formation was seen over $10 \mathrm{wt} \% \mathrm{Ni}$ catalysts (entry 4, Table 3), suggesting that larger $\mathrm{Ni}$ particles $(10.1 \mathrm{~nm})$ are better for ring hydrogenation of FA. Another possibility is that these differences in selectivity could reflect the impact of the porous structure of the carbon support, where the volume of mesopores is substantially higher for $1 \mathrm{wt} \% \mathrm{Ni}$ catalyst, and decreases as the loading of nickel increases. To confirm the need for the Ni in the catalyst, the furfural hydrogenation was performed in its absence, using only $\mathrm{CN}$, which gave poor catalytic activity as well as poor FA selectivity (entry 5, Table 3). Experiments in the absence of the carbon support did not show any activity for FA formation (entry 6 , Table 3). So clearly the complete hydrogenation of furfural to FA was mainly catalyzed by Ni nanoparticles.

\section{Recyclability study}

The recyclability of the $5 \mathrm{wt} \% \mathrm{Ni} / \mathrm{CN}$ catalyst was evaluated by repeating the furfural hydrogenation reaction with the same catalyst (Fig. 6). After the first run, the final reaction mixture was transferred to a centrifuge tube. The liquid phase was decanted, analyzed by GC and the catalyst was washed three times with $30 \mathrm{~mL}$ of 2-propanol. After centrifugation, the liquid phase was separated and the catalyst was dried at $100{ }^{\circ} \mathrm{C}$ for $5 \mathrm{~h}$ and was then reduced under a flow of $\mathrm{H}_{2}$ gas (at $350{ }^{\circ} \mathrm{C}$ for $4 \mathrm{~h}$ ). Subsequently, the catalyst was reused for furfural hydrogenation. The above procedure was repeated three more times. The results given in Fig. 6 clearly demonstrate that the performance of the $5 \mathrm{wt} \% \mathrm{Ni} / \mathrm{CN}$ catalyst is little changed even after being reused four times. TEM analysis of spent catalyst (Fig. 7) shows that Ni particle size is similar to that of the fresh catalyst (Fig. 2e and f). Chemical analysis using ICP-OES showed no leaching of $\mathrm{Ni}$ after each recycle, indicating $\mathrm{Ni}$ nanoparticles are still strongly bound to the CN support. These results indicate good stability of the material under the given reaction conditions.

\section{Mechanistic route for furfural to FA over Ni/CN catalysts}

It has recently been suggested that $\mathrm{Ni}$ metal dissociates $\mathrm{H}_{2}$ molecule into proton and hydride. ${ }^{40}$ In the present study there might be dissociation of the $\mathrm{H}_{2}$ molecules under operating conditions (Scheme 3, step 2). The nucleophilic hydride ion attacks the electrophilic carbon of the carbonyl group in the furfural (Scheme 3, step 3). This phenomenon of electron transfer leads to a mesomeric effect which thereby results in the
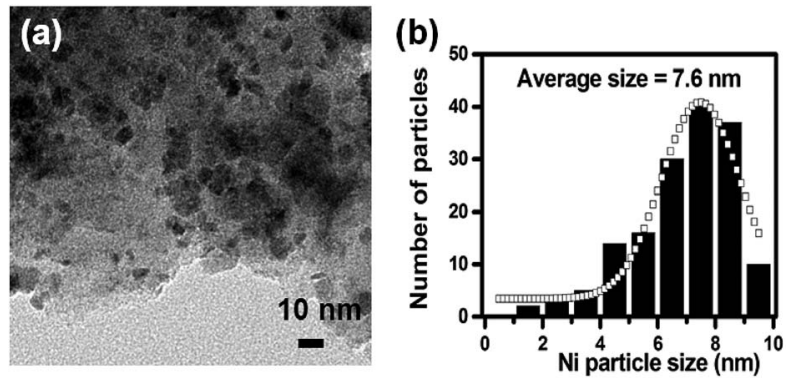

Fig. 7 (a) TEM image and (b) Ni nanoparticles size distribution for spent $5 \mathrm{wt} \% \mathrm{Ni} / \mathrm{CN}$ catalyst (after 4 recycles).

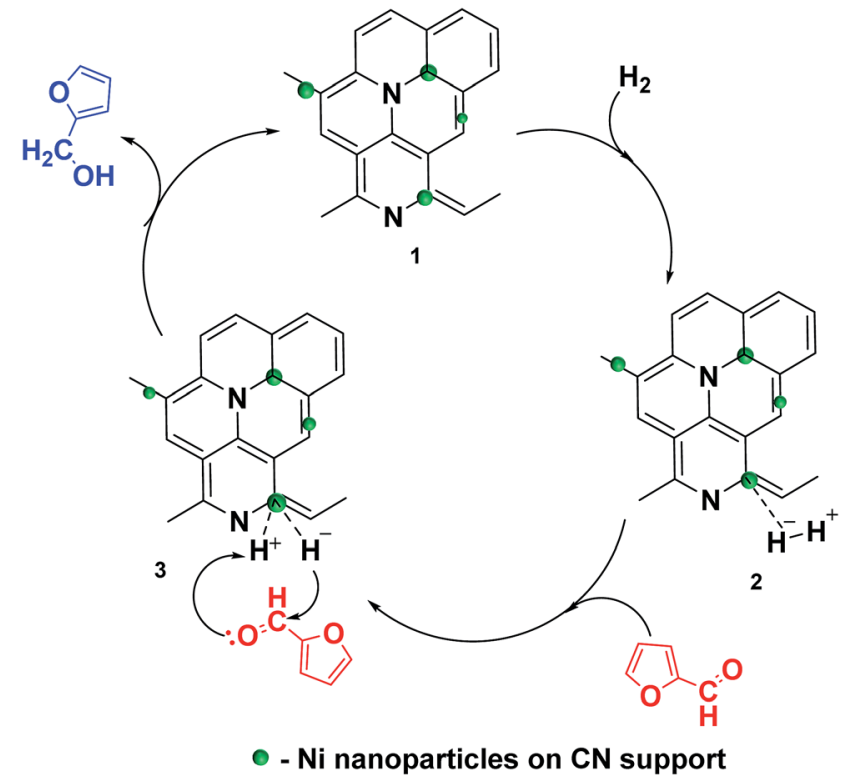

Scheme 3 Plausible mechanistic route for the selective hydrogenation of furfural to FA over $\mathrm{Ni} / \mathrm{CN}$ catalysts.

formation of FA (Scheme 3, step 3). Hierarchically porous carbon network of $\mathrm{Ni} / \mathrm{CN}$ catalysts improves mass transfer of furfural molecules to the Ni nanoparticles and facilities free diffusion of the hydrogenated products. The presence of nitrogen in $\mathrm{CN}$ support stabilized the Ni nanoparticles.

\section{Conclusions}

Nitrogen doped hierarchically porous carbon supported Ni catalysts prepared using a simple one-pot co-gelation sol-gel method showed promising activity for the selective conversion of biomassderived furfural to FA under batch conditions. Under the optimal operating conditions, furfural conversion of 96\% with 95\% selectivity towards FA could be achieved over $5 \mathrm{wt} \% \mathrm{Ni} / \mathrm{CN}$ catalyst. This catalyst was recycled and reused four times without significant loss in activity and FA selectivity. The presence of both meso- and macropores in the $\mathrm{Ni} / \mathrm{CN}$ material is advantageous for heterogeneous catalysis producing efficient mass transport of reactants to the catalytically active site, and removal of products. These materials can be considered for commercial interests in the field of catalysis owing to their shorter synthetic route described herein. The monolithic nature of the $\mathrm{Ni} / \mathrm{CN}^{36}$ catalysts makes them particularly suitable for use in microreactors. The activity of these catalysts will be screened in flow reactors for industrially important organic transformations such as hydrogenations, oxidations, and $\mathrm{C}-\mathrm{C}$ couplings. Metal nanoparticles supported on nitrogen doped hierarchically carbon catalysts offer an efficient, recyclable and selective method for hydrogenation of biomassderived compounds to obtained fine chemicals and fuels.

\section{Conflict of interest}

The University of Alabama has filed a US patent application covering the one-pot co-gelation sol-gel method. 


\section{Acknowledgements}

TVK acknowledges the Research Simulation program at The University of Alabama for support. ASN and HRG acknowledge Council of Scientific and Industrial Research (CSIR), New Delhi, India, for providing senior research fellowships and CMC at CSIR-NCL for assistance in catalyst characterization.

\section{References}

1 (a) G. W. Huber, S. Iborra and A. Corma, Chem. Rev., 2006, 106, 4044-4098; (b) A. Corma, S. Iborra and A. Velty, Chem. Rev., 2007, 107, 2411-2502; (c) J. N. Chheda, G. W. Huber and J. A. Dumesic, Angew. Chem., Int. Ed., 2007, 46, 71647183; (d) K. Shimizu and A. Satsuma, Energy Environ. Sci., 2011, 4, 3140-3153.

2 Y. Nakagawa, M. Tamura and K. Tomishige, ACS Catal., 2013, 3, 2655-2668.

3 R. Karinen, K. Vilonen and M. Niemela, ChemSusChem, 2011, 4, 1002-1016.

4 (a) X. Li, J. Deng, J. Shi, T. Pan, C. Yu, H. Xu and Y. Fu, Green Chem., 2015, 17, 1038-1046; (b) E. I. Gurbuz, S. G. Wettstein and J. A. Dumesic, ChemSusChem, 2012, 5, 383-387.

5 R. V. Sharma, U. Das, R. Sammynaiken and A. K. Dalai, Appl. Catal., A, 2013, 454, 127-136.

6 S. G. Kulkarni, V. S. Bagalkote, S. S. Patil, U. P. Kumar and V. A. Kumar, Propellants, Explos., Pyrotech., 2009, 34, 520525.

7 K. Yan and A. Chen, Energy, 2013, 58, 357-363.

8 S. Sitthisa, T. Sooknoi, Y. Ma, P. B. Balbuena and D. E. Resasco, J. Catal., 2011, 277, 1-13.

9 B. M. Nagaraja, A. H. Padmasri, B. David Raju and K. S. Rama Rao, J. Mol. Catal. A: Chem., 2007, 265, 90-97.

10 J. Kijenski, P. Winiarek, T. Paryjczak, A. Lewicki and A. Mikołajska, Appl. Catal., A, 2002, 233, 171-182.

11 S. Sitthisa and D. E. Resasco, Catal. Lett., 2011, 141, 784-791.

12 V. Vetere, A. B. Merlo, J. F. Ruggera and M. L. Casella, J. Braz. Chem. Soc., 2010, 21, 914-920.

13 W. Huang, H. Li, B. Zhu, Y. Feng, S. Wang and S. Zhang, Ultrason. Sonochem., 2007, 14, 67-74.

14 B. M. Nagaraja, V. Siva Kumar, V. Shasikala, A. H. Padmasri, B. Sreedhar, B. D. Raju and K. S. Rama Rao, Catal. Commun., 2003, 4, 287-293.

15 X. Chen, H. Li, H. Luo and M. Qiao, Appl. Catal., A, 2002, 233, 13-20.

16 R. S. Rao, R. T. Baker and M. A. Vannice, Catal. Lett., 1999, 60, 51-57.

17 R. S. Rao, R. T. Baker and M. A. Vannice, J. Catal., 1997, 171, 406-419.
18 B. M. Nagaraja, A. H. Padmasri, P. Seetharamulu, K. H. P. Reddy, B. D. Raju and K. S. Rama Rao, J. Mol. Catal. A: Chem., 2007, 278, 29-37.

19 O. F. Aldosari, S. Iqbal, P. J. Miedziak, G. L. Brett, D. R. Jones, X. Liu, J. K. Edwards, D. J. Morgan, D. K. Knight and G. J. Hutchings, Catal. Sci. Technol., 2016, 6, 234-242.

20 M. Tamura, K. Tokonami, Y. Nakagawa and K. Tomishige, Chem. Commun., 2013, 49, 7034-7036.

21 S. P. Lee and Y. W. Chen, Ind. Eng. Chem. Res., 1999, 38, 2548-2556.

22 M. Manikandan, A. K. Venugopal, A. S. Nagpure, S. Chilukuri and T. Raja, RSC Adv., 2016, 6, 3888-3898.

23 J. Wu, Y. Shen, C. Liu, H. Wang, C. Geng and Z. Zhang, Catal. Commun., 2005, 6, 633-637.

24 S. Sitthisa, W. An and D. E. Resasco, J. Catal., 2011, 284, 90101.

25 B. M. Nagaraja, A. H. Padmasri, B. D. Raju and K. S. Rama Rao, Int. J. Hydrogen Energy, 2011, 36, 3417-3425.

26 H. Li, H. Luo, S. Zhang, W. Dai and M. Qiao, J. Mol. Catal. A: Chem., 2003, 203, 267-275.

27 H. Li, S. Zhang and H. Luo, Mater. Lett., 2004, 58, 2741-2746. 28 M. L. Toebes, Y. Zhang, J. Hájek, T. A. Nijhuis, J. H. Bitter, A. J. van Dillen, D. Y. Murzin, D. C. Koningsberger and K. P. de Jong, J. Catal., 2004, 226, 215-225.

29 J.-P. Tessonnier, L. Pesant, G. Ehret, M. J. Ledoux and C. Pham-Huu, Appl. Catal., A, 2005, 288, 203-210.

30 M. L. Toebes, T. A. Nijhuis, J. Hájek, J. H. Bitter, A. J. van Dillen, D. Y. Murzin and K. P. de Jong, Chem. Eng. Sci., 2005, 60, 5682-5695.

31 N. Mahata, F. Goncalves, M. F. R. Pereira and J. L. Figueiredo, Appl. Catal., A, 2008, 339, 159-168.

32 S. Gryglewicz, A. Sliwak, J. Cwikła and G. Gryglewicz, Catal. Lett., 2014, 144, 62-69.

33 A. S. Nagpure, L. Gurrala, P. Gogoi and S. V. Chilukuri, RSC Adv., 2016, 6, 44333-44340.

34 B. Zhang and D. S. Su, ChemCatChem, 2015, 7, 3639-3645.

35 Z. Li, J. Liu, C. Xia and F. Li, ACS Catal., 2013, 3, 2440-2448.

36 T. V. Kotbagi, Y. Hakat and M. G. Bakker, Mater. Res. Bull., 2016, 73, 204-210.

37 H. Chen, F. Sun, J. Wang, W. Li, W. Qiao, L. Ling and D. Long, J. Phys. Chem. C, 2013, 117, 8318-8328.

38 J. Hoekstra, A. M. Beale, F. Soulimani, M. Versluijs-Helder, J. W. Geus and L. W. Jenneskens, J. Phys. Chem. C, 2015, 119, 10653-10661.

39 J. Hájek, N. Kumar, P. Mäki-Arvela, T. Salmi and D. Y. Murzin, J. Mol. Catal. A: Chem., 2004, 217, 145-154.

40 A. Halilu, T. H. Ali, A. Y. Atta, P. Sundarsanam, S. K. Bhargava and S. B. A. Hamid, Energy Fuels, 2016, 30, 2216-2226. 